\title{
Pilotage or Conning Radar
}

\author{
J. Watt \\ (The Marconi Company Ltd.)
}

THE paper by Captain J. P. Stewart in the July issue of the Journal, entitled as above, presents a wealth of evidence and argument for the obvious sense of designing marine radars in such a way that they can :

(a) present compass stabilized radar pictures in the natural ship's-head-up orientation. This avoids the mental stress of trying to correlate the radar view and the eye-ball view of the same situation when the two may be presented in completely different orientations;

and

(b) simultaneously allow true bearings of targets to be read off directly.

Unfortunately the fallacy that the benefits of compass stabilization (elimination of errors in bearing observations and of picture smear, due to yawing or alterations in course by own ship) could be available only in a north-up display, and were quite incompatible with a ship's-head-up display, has been prevalent throughout the whole history of marine radar. This in spite of the fact that one manufacturer (R.C.A.) came out in about 1960 with the 'True View' radar which presented a fully compass-stabilized, and if desired true-motion, display in ship's-head-up orientation. Another manufacturer (Marconi) in 1962 produced the Argus radar which provided compass stabilization of the radar picture and of the tracks on the reflection plotter, direct presentation of true bearings, and true motion, all in either ship's-head-up or north-up orientation of the radar picture as selected by a switch on the front panel. The orientation selected would depend upon whether the radar was being used mainly in association with visual observation or for navigation in close comparison with the chart. The Argus radar was substantially Captain Stewart's final refinement proposed in (2) on the last page of his paper. Further discussion on this problem and a description of the Argus rotating tube solution were given by Mr. J. A. Glasgow in a contribution to Forum entitled 'Radar Displays' in the April 1964 issue of the Journal.

The same philosophy of providing all the benefits of compass stabilization with the display in either ship's-head-up or north-up orientation as desired has been followed in the design of the Marconi Predictor self-plotting radar described in a paper presented to the Institute on 15 January this year. It is of interest that, in a contribution to the discussion on that paper published in the April 1969 issue of the Journal, Captain R. H. Farrands reported that, in 1964, the European Maritime Pilots Association advocated the Argus form of radar display which, by means of a rotating (i.e. compass stabilized) cathode-ray-tube, gave a ship'shead-up presentation of true motion.

I am thus basically very much in agreement with Captain Stewart. However, I feel that, in view of the fact that compass data in electrical form is already present in the display unit in order to permit the primary stablization of North on the C.R.T. screen, and the tube is rotatable, the designer might just as well 'go the 
whole hog' and provide automatic stabilization of the tube in accordance with his (2) on page 359 . This in fact was done in both the Argus and Predictor radars.

My only serious criticism of Captain Stewart's proposals is his suggested inclusion of a relative bearing scale. Our view has been that, so long as the radar provides means for accurately reading off true bearings, and means for placing a marker on a desired compass bearing upon which it will then remain constant regardless of yawing or alteration in course, there is no necessity in merchant ships for any means on the radar for reading off relative bearings. Elimination of the relative bearing scale makes for greater clarity, and makes impossible the blunder of reading one scale in mistake for the other.

Information coming back to us from sea, where Argus stabilized screen radar has been in use for 7 years, strongly suggests that there is no real need for a relative bearing scale in addition to a true bearing scale. Similarly in regard to the self-plotting radar Predictor, this has now been used in earnest and critically examined by about a score of sea-going officers and specialists. Although there have been plenty of suggestions for improvements in the arrangement of controls, most of which have been adopted, not a single officer has lamented the absence in any form of a relative bearing scale. The picture itself, when operated ship'shead-up, provides relative bearing indications rather than precise readings, and these in respect of relative bearings are all that are needed.

\section{Sailing Vessels and the Collision Regulations}

\section{Michael Richey}

IT is to be hoped that before the Collision Regulations are revised in any sense that affects the rights and obligations of sailing vessels, people with practical experience of navigation under sail will be consulted. It looks as though their advice will be needed.

One increasingly hears, for example, that under modern conditions steam should no longer be required to give way to sail. 'It seems quite unreasonable now'-Captain Dickson, for instance, expresses it in the last number of the Journal $(\mathbf{2 2}, 448)$-'to expect in most cases that sailing vessels should be required to stand on for power-driven vessels'. But the reason a power-driven vessel is required to give way to sail is not some kind of old world courtesy, but that if there is no wind, the sailing vessel is immobilized: it cannot give way.

Again in the current number (p. 89) Captain Thompson in the course of his excellent cockshy at a revised set of Collision Regulations would omit, in his Rule 4, any distinction between the rights of sailing vessels running free and close-hauled. But anyone who has made up to windward in a sailing vessel knows how much more ground stands to be lost by an alteration of course by a vessel close-hauled than one running free.

These are only two examples of how things can be seen too exclusively from a steamship point of view. But the overriding need at the moment is for a thorough 